\section{Microscopy \& Microanalysis 2022 in Portland, OR}

\author{
Eric Stach, Program Chair \\ University of Pennsylvania
}

MM2022ProgramChair@microscopy.org

\section{MNation MICROSCOPY \& MICROANALYSIS July 31-August 4. Portland, OR}

The Microscopy Society of America (MSA) and the Microanalysis Society (MAS) invite you to attend Microscopy \& Microanalysis 2022 (M\&M 2022) in Portland, OR July 31-August 4, 2022. Portland is a wonderful place for a summertime conference-ideal weather, a beautiful setting, convenient transportation, and a cosmopolitan yet navigable city. The Pacific Northwest region is full of activities for both lovers of the outdoors and for urban adventurers. Tax-free shopping, countless local breweries, distilleries, wineries, and dispensaries (if you care to partake!); one of America's great dining scenes featuring innovative restaurants, and access to the Cascade and Olympic National Parks, the picturesque Oregon Coast, and the stunning Columbia River Gorge (Figure 1). Portland is consistently one of the best-attended M\&M meetings for these reasons.

We are excited to welcome you to another great M\&M meeting! We are fully anticipating that M\&M 2022 will be an in-person meeting, in contrast to the successful virtual programs of 2020 and 2021. The scientific content of M\&M 2022 will feature outstanding plenary speakers, symposia, pre-meeting and in-meeting educational opportunities, and, of course, a range of social events to enhance the meeting experience.

The conference will begin with the MSA Student Council's PreMeeting Congress highlighting outstanding work by students, postdoctoral fellows, and early career professionals. Two other Pre-Meeting Congresses will feature: "Pharmaceutical, Biopharmaceutical, and Medical Health Products" sponsored by the Pharmaceuticals Focused Interest Group (FIG), and "RealWorld Data Analytics \& Quantitative Liquid and Gas Environmental Electron Microscopy" sponsored by the Electron Microscopy in Liquids and Gases FIG. These pre-meeting events will be complemented by eight Sunday Short Courses that will cover various topics, including high-resolution structure determination by cryo-EM, fluorescence microscopy in biological imaging, SerialEM, in situ and operando approaches
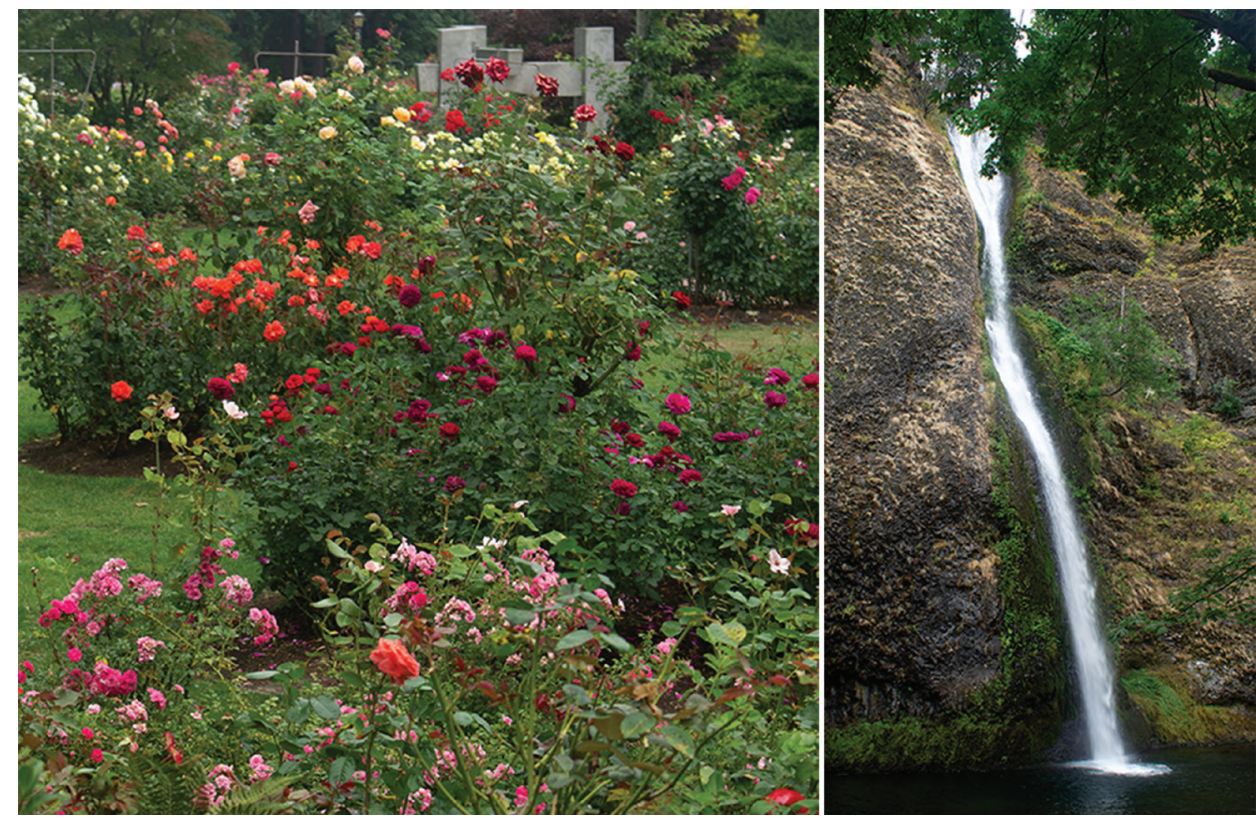

Figure 1: Portland and the surrounding area feature natural beauty, including the Portland International Rose Test Garden and Horsetail Falls. Photos courtesy of Bev Maleeff. 


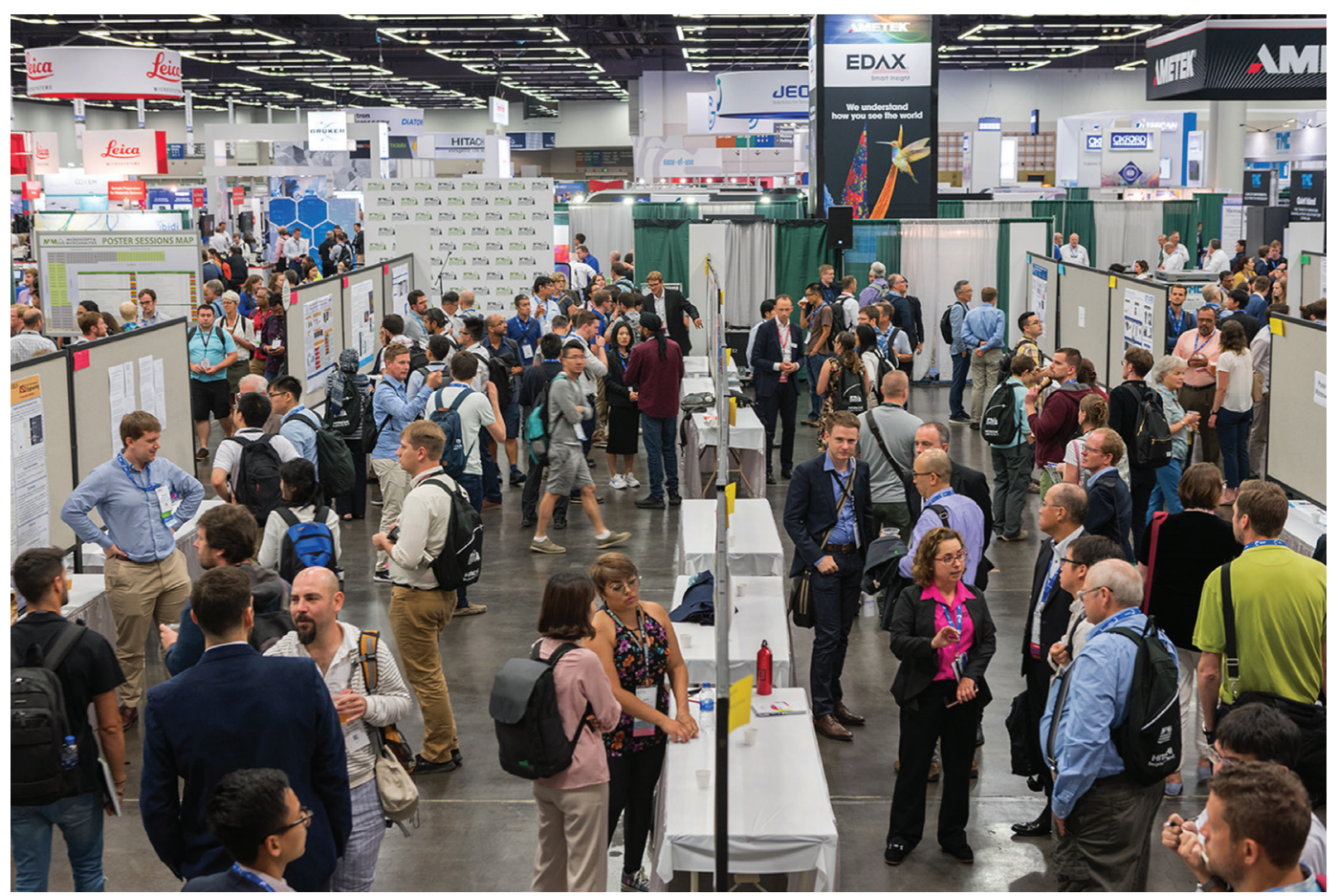

Figure 2: Symposium-associated poster sessions are held daily in the Exhibit Hall. This image is from Microscopy \& Microanalysis 2019 in Portland, OR.

Forum-sponsored events. Technologists' Forum topics include roundtable discussions on Image Data Analysis Software Review, 3D SEM Techniques, and a workshop on Tissue Clearing Tips \& Techniques.

Finally, there will be a full complement of Microscopy Outreach sessions in Portland: ProjectMICRO, our popular microscopy outreach workshop, will be in the MegaBooth all week. See different microscope systems and learning stations for use in the classroom, peruse books suitable for elementary school-age children, and share your experiences of how to have fun with microscopy. Microscopy in the Classroom will continue with its "STEM Roundtable" session. Come join the conversation with educators, industry leaders, and other key

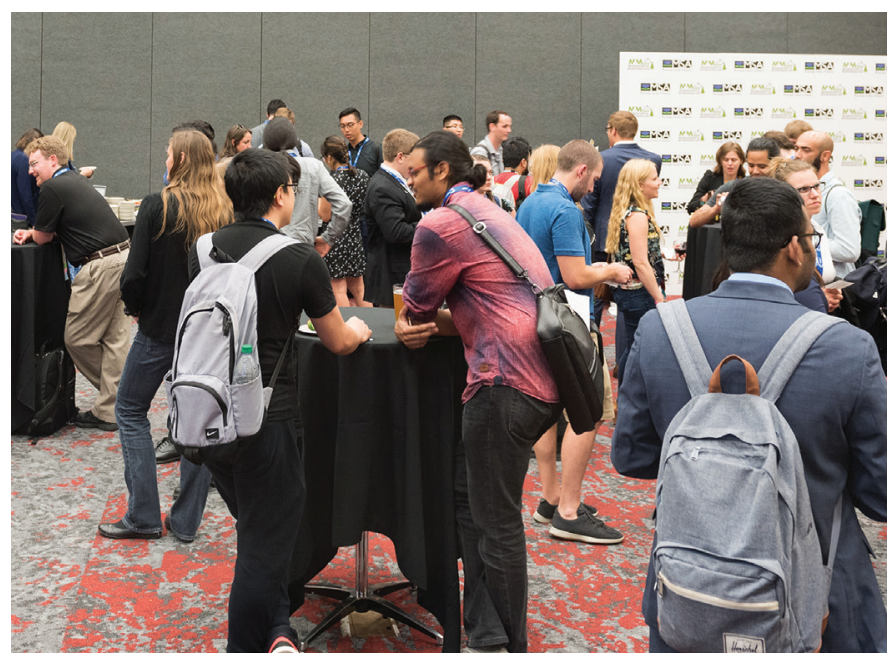

Figure 3: The Student Mixer at Microscopy \& Microanalysis 2019. stakeholders who are invested in STEM education! Microscopy in the Classroom provides a unique educational experience for high school and undergraduate students outside the traditional classroom. Microscopy Explorations for Families and Kids of All Ages (formerly Family Affair) returns for another year of on-site microscopy games, exploration, and fun!

A large number of social activities await you in Portland, including the opening reception, intermission at the Plenary session, refreshments during the daily poster sessions (Figure 2), student and postdoctoral scholar mixers (Figure 3), and many vendor-sponsored events. Prize-winning student posters will be announced each day, in addition to an award for the best poster utilizing ultramicrotomy, the Microscopy Today Innovation Awards and micrograph contest, and the very popular Passport to Prizes with some outstanding gifts sponsored by our exhibitors.

For a complete description of the M\&M 2022 technical program and educational opportunities, please go to https:// www.microscopy.org/MandM/2022. Please note that to keep all attendees safe, as well as to comply with existing Portland regulations, M\&M 2022 will require proof of vaccination, as well as the use of face masks inside of the Oregon Convention Center, as well as at other M\&M-affiliated events. Details regarding the proof of vaccination requirement are being finalized at present and will be conveyed well in advance of the meeting.

The Executive Program Committee welcomes you to attend M\&M 2022 for an extraordinary and compelling event. Join us to catch up with old friends and make new ones! On behalf of MSA and MAS, in cooperation with over one hundred symposium organizers and countless volunteers, we look forward to seeing you in Portland this summer! 